Revista Destaques Acadêmicos, Lajeado, v. 9, n. 2, 2017. ISSN 2176-3070

DOI: http://dx.doi.org/10.22410/issn.2176-3070.v9i2a2017.1314

www.univates.br/revistas

\title{
AS POSSIBILIDADES DE ALTERAÇÃO DO NOME CIVIL DAS PESSOAS NATURAIS
}

\author{
Guilherme de Paoli Schmidt ${ }^{1}$, Beatris Francisca Chemin ${ }^{2}$
}

Resumo: O nome é elemento essencial para identificação do indivíduo na família e na sociedade, devendo, em regra, ser imutável, de modo a proteger as relações jurídicas; contudo, aparecem situações na vida da pessoa que pedem mudança dessa regra. Nesse sentido, este artigo tem por objetivo analisar as possibilidades de alteração do nome civil da pessoa natural. Trata-se de pesquisa qualitativa, realizada por meio de método dedutivo e de procedimento bibliográfico e documental. Inicialmente, o texto trata dos direitos de personalidade, descrevendo conceitos, o contexto histórico com a previsão no ordenamento jurídico brasileiro e suas principais características. Após, estuda aspectos do nome civil, elemento fundamental para a identificação e individualização de cada indivíduo, descrevendo conceitos, considerações históricas e natureza jurídica da proteção no nome, bem como a identificação de seus elementos obrigatórios e secundários. Por fim, examina possibilidades de mudança do nome, à luz da legislação, doutrina e jurisprudência, abordando casos que autorizam a mudança do prenome, do nome de família, além de outras situações. Assim, conclui que tem havido certa flexibilidade na regra da imutabilidade do nome, fazendo com que a alteração se adapte ao desenvolvimento da sociedade, em que nela o nome é fator de identificação e individualização, para garantia das pessoas no seu convívio pessoal, em sociedade e com o Estado.

Palavras-chave: Direitos de personalidade. Nome civil. Alterações do nome da pessoa natural.

\section{INTRODUÇÃO}

Para as pessoas serem identificadas nos seus direitos e deveres na ordem civil, é importante que sejam individualizadas, sendo que essa individualização se dá por vários elementos, entre eles, principalmente, o estado, que indica a

1 Acadêmico formando do Curso de Direito do Centro Universitário UNIVATES. E-mail: guipschmidt@gmail.com

2 Professora do Curso de Direito do Centro Universitário UNIVATES. Mestre em Direito. E-mail: bchemin@univates.br 
posição na família e na sociedade em geral; o domicílio, que é a sede jurídica dessa pessoa, e o nome, que é a designação que a diferencia dos demais conviventes privados e públicos, objeto deste estudo.

O nome, normalmente composto pelo prenome e sobrenome, é uma característica social da pessoa natural. Ele integra a personalidade, sendo peça fundamental para identificação e individualização diante de outros indivíduos na família, na sociedade e no Estado. Da mesma forma, tem proteção jurídica, tanto em vida quanto após a morte. Inicia-se com o registro, que deve ser realizado no lugar em que tiver ocorrido o nascimento ou no lugar da residência dos pais, conforme a Lei 6.015/1973, conhecida como Lei dos Registros Públicos (LRP), sendo o nome um direito de cada indivíduo, preceituado pelo Código Civil (CC) em artigos do capítulo que trata dos direitos da personalidade.

Nesse sentido, este artigo terá como objetivo geral analisar as possibilidades de alteração do nome civil da pessoa natural, discutindo como problema: tendo em vista a regra geral da imutabilidade do nome da pessoa natural, em quais casos é permitida a mudança dessa identificação social? Como hipótese, entende-se ser autorizada a alteração do nome em algumas situações, como erro gráfico, nome ridículo, apelido público notório, com o casamento, adoção, reconhecimento de paternidade, dentre outras específicas, desde que justificadas judicial e/ou extrajudicialmente, dependendo do caso.

A pesquisa, quanto à abordagem, será qualitativa, que tem como característica o aprofundamento no contexto estudado e a perspectiva interpretativa desses dados para a realidade, conforme esclarecem Mezzaroba e Monteiro (2014). Para obter a finalidade desejada pelo estudo, será empregado o método dedutivo, cuja operacionalização se dará por meio de procedimentos técnicos baseados em recursos bibliográficos e documentais, misturando-se doutrina, legislação e jurisprudência, relacionados, inicialmente, aos direitos de personalidade, passando pelo estudo do nome civil, para chegar ao ponto principal do trabalho, as possibilidades de mudança desse nome da pessoa natural.

\section{DIREITOS DE PERSONALIDADE}

Toda pessoa tem como característica a personalidade, se tornando, assim, titular de direitos e deveres. Tratando sobre a proteção aos direitos de personalidade, o respeito à dignidade humana é prioridade entre os fundamentos constitucionais, trazidos pelo inciso III do artigo $1^{\circ}$ da Constituição Federal e pelo artigo 12, caput, do Código Civil, no sentido de se poder exigir que cesse a ameaça ou a lesão a direito da personalidade, inclusive reclamando perdas e danos ou outras sanções. Diante disso, é objetivo desta seção identificar aspectos sobre os direitos de personalidade, descrevendo o contexto histórico com a previsão no ordenamento jurídico brasileiro e suas principais características. 


\subsection{Conceitos e contexto histórico dos direitos da personalidade}

Conceitualmente, de modo geral, entende-se que direitos da personalidade são direitos de a pessoa resguardar o que lhe pertence por ser uma pessoa humana, ou seja, de direitos que nascem e morrem quando a própria pessoa nasce ou morre de fato. Destacam-se como direitos básicos o direito à vida, à liberdade, à honra, ao próprio nome etc.

Sobre a parte histórica dos direitos da personalidade, Diniz (2009, p. 118) explica a tutela de tais direitos na Antiguidade, punindo ofensas físicas e morais à pessoa, tanto na Grécia quanto em Roma, até chegar à Declaração dos Direitos de 1789, "que impulsionou a defesa dos direitos individuais e a valorização da pessoa humana e da liberdade do cidadão", acrescentando que foi demorada a afirmação desses direitos e sua tutela diante do ordenamento brasileiro, pois apenas em fins do século XX se pôde construir a dogmática dos direitos de personalidade.

No Brasil, a Constituição Federal de 1988 (CF/1988) tutelou normas sobre os direitos de personalidade, destacando-se o artigo $5^{\circ}$, inciso $\mathrm{X}$, que dispõe que "são invioláveis a intimidade, a vida privada, a honra e a imagem das pessoas, assegurado o direito a indenização pelo dano material ou moral decorrente de sua violação".

Além da norma presente, Venosa (2012) destaca que também os princípios, de forma genérica, estão presentes tanto na Constituição, quanto no Código Civil (CC); enquanto na Constituição é apontada a base, o CC as complementa, especificando-as. O CC trata dos direitos da personalidade, dispostos no Capítulo II, em onze artigos, mais especificamente do artigo 11 ao 21. Para Gonçalves (2014), sobre o referido capítulo que foi novidade no CC de 2002, o fato representou progresso, colocando-o entre os mais avançados do mundo.

Já Diniz (2009, p. 125) acredita que pouco foi trabalhado no CC o instituto dos direitos da personalidade, apesar de considerar certo não enumerar direitos, visto o desenvolvimento futuro do tema:

Apesar da grande importância dos direitos da personalidade, o Código Civil, mesmo tendo dedicado a eles um capítulo, pouco desenvolveu sobre tão relevante temática, embora, com o objetivo primordial de preservar o respeito à pessoa e aos direitos protegidos constitucionalmente, não tenha assumido o risco de uma enumeração taxativa prevendo em poucas normas a proteção de certos direitos inerentes ao ser humano, talvez para que haja, posteriormente, desenvolvimento jurisprudencial e doutrinário e regulamentação por normas especiais.

Fiuza (2014, p. 215) também menciona que o tema foi pouco tratado no CC de 2002: 
Não se pode dizer que o Diploma Civil contenha, de forma clara, uma cláusula geral de tutela da personalidade. Limita-se a dispor que os direitos da personalidade são intransmissíveis e irrenunciáveis, não podendo sofrer limitações voluntárias em seu exercício. Além disso, prevê a possibilidade de se exigir que cesse qualquer ameaça a esses direitos, além da indenização por lesão que venhas a sofrer.

Ainda que não se tenha uma considerável relevância no atual CC, os direitos da personalidade sequer tinham um capítulo dedicado a eles no CC de 1916, apenas com alguns princípios nítidos de direitos ligados à personalidade humana, conforme Venosa (2012, p. 177):

A matéria não é tratada sistematicamente na maioria dos códigos civis, e nosso provecto Código de 1916 não era exceção, embora a doutrina não tão recente já com ela se preocupasse. No entanto, somente nas últimas décadas do século XX o direito privado passou a ocupar-se dos direitos da personalidade mais detidamente, talvez porque o centro de proteção dos direitos individuais situase no direito público, no plano constitucional. Aponta-se, contudo, que nosso código do século XX trazia alguns princípios nítidos de proteção à personalidade, como, por exemplo, referências à imagem (art. 666) e ao direito do nome do autor de obra (arts. 449 ss). A legislação esparsa também enunciava muitos direitos dessa natureza.

Com isso, percebe-se que a Constituição Federal, por se tratar principalmente de um direito do ramo público, se preocupou em dar destaque aos direitos da personalidade, visto sua importância para os indivíduos, enquanto no direito civil, ramo do direito privado, o assunto foi menos trabalhado, mas não exatamente pela sua menor importância, mas para não os restringir, visto que são direitos sempre em evolução.

\subsection{Características dos direitos da personalidade}

O artigo 11 do Código Civil dispõe sobre as características dos direitos da personalidade, trazendo que são intransmissíveis e irrenunciáveis, além de que seu exercício não poder sofrer qualquer tipo de limitação voluntária. Contudo, não são apenas essas acima mencionadas as características. A doutrina traz alguns outros atributos:

a) absolutos: os direitos da personalidade tem caráter absoluto por consequência de sua oponibilidade erga omnes, ou seja, contra todos; por sua relevância, estabelecem a todos um dever de respeito e de privação; têm caráter geral, pois são inseparáveis da pessoa humana (GONÇALVES, 2014); 
b) ilimitados: não se podem limitar os direitos da personalidade em apenas alguns artigos, conforme o rol de artigos que consta no Código Civil. Para Diniz (2009), além de confirmar a não limitação, acrescenta que não se pode prever um número fechado desses direitos, diante de novas conquistas biotecnológicas e do progresso econômico e social que possam acrescentar à pessoa ainda mais direitos de personalidade;

c) imprescritíveis: Gonçalves (2012) acentua que essa característica é lembrada, porque esses direitos não se extinguem pelo seu uso ou com o passar do tempo, nem pela falta de ação por parte de seu titular na pretensão de defendê-los. Para Fiuza (2014, p. 2.017), são imprescritíveis "por não haver prazo para seu exercício. As ações que os protegem tampouco se sujeitam a prazo";

d) vitalícios: os direitos da personalidade são vitalícios, pois nascem com a pessoa e relativamente acabam com sua morte; relativamente, pois se resguardam os direitos dos mortos;

e) indisponíveis: via de regra, tais direitos não mudam de titular, não sendo possível transferi-los a outra pessoa. Contudo, conforme Fiuza (2014, p. 206), alguns podem vir a ser disponíveis, desde que sejam por contratos com autorização expressa, licença ou por doação, como os direitos autorais, à imagem, ao corpo e/ou órgãos, dentre outros;

f) extrapatrimoniais: pela impossibilidade de se estimar um valor econômico, assim, sendo impossível reparação in natura ou a recolocação do status quo ante, será a pessoa indenizada por equivalente (DINIZ, 2009);

g) intransmissíveis e irrenunciáveis: essas duas características são as únicas mencionadas expressamente no Código Civil, no art. 11.

Conforme Diniz (2009, p. 121), se referindo a essas características, "são intransmissíveis, visto não poderem ser transferidos à esfera jurídica de outrem. Nascem e se extinguem ope legis com o seu titular, por serem dele inseparáveis. Deveras, ninguém pode usufruir em nome de outra pessoa bens como a vida, a liberdade, a honra etc." e "são irrenunciáveis já que não poderão ultrapassar a esfera de seu titular" (p. 121). Para Gonçalves (2014), a intransmissibilidade e a irrenunciabilidade acarretam a indisponibilidade dos direitos da personalidade, não se podendo delas dispor, renunciar, repassar a terceiros ou abandoná-las. Tais características nascem e morrem com a pessoa titular, visto que nenhuma outra pode usar de direitos como a vida e/ou a honra, não sendo sua mesmo;

h) inexpropriáveis: os direitos da personalidade não estão sujeitos à desapropriação, pois são inseparáveis da pessoa titular, não se podendo retirar do indivíduo contra a sua vontade, assim como não é possível qualquer limitação voluntária em seu exercício (GONÇALVES, 2014); 
i) impenhoráveis: os direitos da personalidade não são passíveis de penhora, conforme Gonçalves (2014, p. 189), pois "se os direitos da personalidade são inerentes à pessoa humana e delas inseparáveis, e por essa razão indisponíveis, certamente não podem ser penhorados, pois a constrição é o ato inicial da venda forçada determinada pelo juiz para satisfazer o crédito do exequente".

Vê-se, então, quanto às características dos direitos da personalidade, o tamanho da sua importância no ordenamento jurídico. Dá-se mais importância na Constituição Federal, ou seja, no cenário do direito público, mais abrangente, com menos ênfase no direito privado, que é mais específico. Nesse contexto, a garantia de proteção dos direitos da pessoa humana é dever do Estado, mas cabe a cada indivíduo o direito de se defender perante a sociedade e o Estado, e o dever de respeitar o próximo, sempre agindo conforme a dignidade da pessoa humana.

\section{O NOME CIVIL DA PESSOA NATURAL}

Individualiza-se a pessoa natural pelo nome, estado e domicílio. $\mathrm{O}$ nome é um dos principais modos de identificação da pessoa humana, elemento essencial para a estruturação da personalidade. Além disso, ter um nome é um direito fundamental, em respeito ao princípio da dignidade da pessoa humana. O direito ao nome está disposto no Código Civil, em seus artigos 16 a 19, bem como na Lei dos Registros Públicos (Lei 6.015/1973), em vários dispositivos. Assim, esta seção tem por objetivo descrever conceitos, considerações históricas e natureza jurídica da proteção ao nome, bem como identificar seus elementos obrigatórios e secundários.

\subsection{Conceitos e considerações históricas}

O nome é elemento fundamental para a identificação da pessoa, iniciando com o registro, normalmente acontecendo após o nascimento, e a acompanhando em toda a sua vida, inclusive com certa proteção até após a morte. É direito fundamental de grande importância, permitindo que se garanta respeito aos demais direitos da pessoa, e atribuindo deveres, para que possa individualizá-la em relação aos demais perante a sociedade, não a confundindo com outro indivíduo (BRANDELLI, 2012).

Gonçalves (2010, p. 148) conceitua o nome como uma "designação ou sinal exterior pelo qual a pessoa identifica-se no seio da família ou da sociedade". Para Venosa (2012), o nome que se dá à pessoa humana é um dos principais direitos contidos na esfera dos direitos da personalidade, situando sua importância na mesma categoria de seu estado, capacidade civil e dos outros direitos ligados à personalidade; nas sociedades mais antigas, um único nome era o bastante para identificar o indivíduo no local. Para melhor 
identificar cada pessoa, tomava-se como referência a família, o local onde residia e características próprias da pessoa.

Rizzardo (2005, p. 182) destaca aspectos histórico-evolutivos do nome:

Sempre existiu uma forma de chamar os seres humanos, desde as suas primeiras manifestações históricas. Nos povos antigos, havia apenas um nome utilizado para a designação. Assim, entre os gregos, como revelam os livros de história, mantendo-se conhecidos os filósofos Sócrates, Platão, Aristóteles, Demóstenes, Péricles. Igualmente entre os hebreus, onde se apresentava um nome, mas sempre com a referência ao pai, como Abidau, filho de Gedeão; Abraão, filho de Terá; Isaac, filho de Abraão; Rebeca, filha de Batuel. No tempo do Império Romano, adotou-se um prenome, ou um indicativo da pessoa, acrescentado ao nome da gens, do tronco antigo, e de um cognome, que era o designativo da família. Isto quanto aos nobres, que procuravam remontar a origem de antigas famílias, como 'Marco Túlio Cícero' - sendo 'Marco' o apelido, Túlio a 'gens', e 'Cícero' o cognome da família, segundo rememoram os tratadistas. Já quem não pertencia à nobreza, vindo da plebe, designava-se através de apenas um nome.

Dessa forma, enfatiza o doutrinador que com o intuito de diferenciar as pessoas que possuíam o mesmo nome e para evitar certa desordem na identificação individual, o que foi se tornando mais comum com o passar dos tempos, surgiu a designação pela formação de dois ou mais nomes, se tornando comum na Idade Média.

Destaca Rizzardo (2005, p. 181) que o nome, além de ser uma expressão de identificação, também revela toda uma história do indivíduo:

[...] mais que uma simples palavra que serve para destacar as pessoas entre si, passa a constituir um patrimônio, um símbolo de valor, revela uma história, uma realidade de acordo com o desempenho de quem representa. Os que passaram pela história e permaneceram, as pessoas famosas, os conquistadores, os sábios, os que sobressaíram, e mesmo os maiores criminosos, os que a história condenou e repudiou, continuam conhecidos porque vinculam a um nome.

Portanto, nos tempos atuais, com o grande crescimento da população, o nome é elemento essencial para identificação e individualização de cada pessoa, tanto para a sociedade quanto para o Estado, a fim de que se possa garantir os direitos e impor os deveres inerentes a cada um. Assim, percebe-se a maior relevância que o nome foi adquirindo com o passar do tempo, tornandose elemento fundamental de identificação e individualização de cada pessoa. 


\subsection{Proteção e natureza jurídica do nome}

Atualmente, na legislação brasileira, o direito ao nome está previsto na Constituição Federal, de uma forma mais genérica, encontrada no artigo $5^{\circ}, \mathrm{X}$, que trata sobre a inviolabilidade da honra e imagem da pessoa; no Código Civil, de forma mais específica, como se verá a seguir; e também na Lei 6.015/1973, a Lei dos Registros Públicos, que trata do assunto mais minuciosamente.

O direito ao nome está disposto pelo Código Civil, em seu artigo 16, trazendo que "toda pessoa tem direito ao nome, nele compreendidos o prenome e o sobrenome". Já no artigo 17, "o nome da pessoa não pode ser empregado por outrem em publicações ou representações que a exponham ao desprezo público, ainda quando não haja intenção difamatória". O artigo 18 dispõe que "sem autorização, não se pode usar o nome alheio em propaganda comercial". O principal objetivo da propaganda é o aumento nas vendas de produtos ou serviços, seja ela institucional (criar imagem positiva do produto), seja de promoção de certames (premiando consumidores). Assim, a citação de certo nome juntamente com o produto a ser ofertado busca o crescimento das vendas perante os consumidores. Por isso deve o nome receber proteção, devendo a pessoa, famosa ou não, autorizar o uso de seu nome para ser explorado comercialmente, principalmente por terceiros (COELHO, 2010).

De fato, o nome representa a melhor forma de expressão para se identificar uma pessoa, constitui um direito que pertence ao portador, e, por isso, merece proteção. Há diversas teorias existentes sobre a natureza jurídica, em que, entre as principais, destacam-se a teoria negativista, do nome como propriedade, da polícia civil e da teoria do direito à personalidade.

Para explicar um pouco sobre cada teoria da natureza jurídica, dispõe Brandelli (2012, texto digital) sobre a teoria negativista de que não existe um direito ao nome; da teoria do nome como propriedade de que essa "parte da premissa maior de que o direito de propriedade pode versar tanto a respeito de bens materiais como imateriais, e aqui se incluiria o direito ao nome, posto que a pessoa adquire o nome e dispõe dele com exclusão das demais"; da teoria da polícia civil, afirmando que o nome não seria um direito de cada indivíduo, mas sim uma obrigação ou exigência de ordem pública; e da teoria do direito da personalidade de "que se trata o nome de uma exteriorização da personalidade do indivíduo. Daí ser o nome um dos direitos da personalidade, inerentes ao ser humano" (texto digital).

Da teoria da personalidade, destaca Amorim (2012, p. 8) que "a lei assegura o direito ao nome, assim como seu registro em local adequado, obedecidas as formalidades, criando a particularização da pessoa, no mundo jurídico. Ele faz, pois, parte integrante da personalidade".

Como visto, o nome tem proteção no ordenamento jurídico brasileiro, tendo como natureza jurídica mais adequada a teoria da personalidade. 


\subsection{Elementos obrigatórios e secundários do nome}

Aos elementos que compõem o nome, preceitua o artigo 16 do CC que a formação compreende o prenome e o nome de família, designado também de sobrenome, ou seja, a presença do prenome e do sobrenome é obrigatória, sendo considerados fundamentais para a formação do nome civil. Contudo, não são apenas essas duas as possíveis designações que vêm a compreender, de regra, o nome civil. Os elementos secundários são elementos não obrigatórios no nome da pessoa, podendo eles estarem ou não na designação, tendo a função de apenas complementar, pois mesmo sem o seu uso o nome estará completo.

Quanto à sua utilidade, explica Brandelli (2012, texto digital) que se usados como elementos individualizadores, acabam por integrar o nome do indivíduo:

Sua inclusão no nome não é obrigatória, ainda que a eles tenha direito o titular do nome, porém, se usados de maneira que se constituam elemento identificador pessoal, acabam por integrar-se ao nome, funcionando aí como elementos seus, elementos secundários.

O prenome, que se conhece pela palavra nome, que também pode ser chamado por nome de batismo, é o primeiro elemento do nosso nome quando completo. Trata-se da forma mais simples de individualizar a pessoa e o modo pelo qual geralmente cada indivíduo é conhecido perante todos. Destaca Brandelli (2012, p. 91) que "se é o nome de família que identifica os membros integrantes de certa família, é o prenome quem, dentro da família, distingue seus componentes, fazendo-o também em relação à coletividade".

Já o nome de família é o que se conhece pelo vocábulo sobrenome, podendo ser chamado também como patronímico. O nome de família tem o condão de identificar a qual família pertence o indivíduo. Enquanto que o prenome se refere diretamente à pessoa, individualizando-a das outras de um modo geral, o nome de família o identifica a qual família o sujeito pertence, mostrando também qual sua origem familiar (BRANDELLI, 2012).

Por sua vez, agnome é o elemento que se acrescenta a um nome por último, ou seja, logo após a complementação do nome do indivíduo; habitualmente, é usado para complementar um nome que geralmente é o mesmo de algum parente, que contenha um significado especial: Júnior, Sobrinho, Neto, são usados para diferenciar as pessoas, ao mesmo tempo que determinam qual a relação parental entre eles (BRANDELLI, 2012).

O apelido ou alcunha é a palavra ligada ao nome do indivíduo, ou usada para substituí-lo, normalmente advinda de características da própria pessoa, do seu trabalho, costumes e manias, ou de qualquer outro motivo. Pode ele ser pejorativo, afetivo, do diminutivo ou aumentativo do nome, de outras características do próprio nome etc. (BRANDELLI, 2012). Para Amorim (2003, p. 15), geralmente "são atribuídos com a intenção de depreciar, ofender, 
caracterizar ou menosprezar as pessoas, porém podem ser motivos de glória, ostentadas como verdadeiro título, dada a notoriedade ou celebridade criada $[\ldots]^{\prime \prime}$.

Hipocorístico é a parte que se retira do nome da pessoa, geralmente o reduzindo ou o colocando no diminutivo: "Sua constituição pode decorrer da mutilação do nome original, mantendo-se as sílabas tônicas (Zé, de José); ou as sílabas átonas (Filó, de Filomena); ou as sílabas preponderantes (Tião, de Sebastião)" (AMORIM, 2003, p. 16). Completa o autor que pode também acontecer reduplicação, como Zezé, Lulu, dentre outros.

Nome vocatório é o elemento pelo qual o indivíduo passa a ser conhecido, situação em que se abrevia o nome completo da pessoa, sendo ela reconhecida, por exemplo, pelo primeiro e último nome, como Olavo Braz Martins dos Guimarães Bilac, que era chamado apenas por Olavo Bilac, ou usando siglas, como J. K. Rowling, para Joanne Kathleen Rowling, dentre outras possibilidades (DINIZ, 2009).

A pessoa que deseja proteção do seu verdadeiro nome usando nome diverso ao seu tem esse nome fictício chamado de pseudônimo, tendo garantia no CC, em seu artigo 19: "o pseudônimo adotado para atividades lícitas goza da proteção que se dá ao nome".

Os heterônimos são os nomes imaginários, geralmente elaborados por artistas e escritores, sendo usados em obras literárias ou artigos, caracterizandoas com ideologias próprias, mas sem se misturar com a do seu titular (AMORIM, 2003).

Há os chamados axiônimos que, para Venosa (2012), são títulos nobiliárquicos e honoríficos, acrescentados antes do prenome, como, por exemplo, conde e comendador; também existem os títulos eclesiásticos, que se trata de um elemento com pouca relevância jurídica, usando como exemplos padre, cardeal, entre outros.

Qualificativos de dignidade oficial e títulos acadêmicos e científicos são elementos que, respectivamente, são atribuídos ao nome pelo fato de a pessoa ser autoridade de Estado ou ter qualidade acadêmica, como exemplo os qualificativos de dignidade oficial, as palavras senador, deputado, ministro entre outros, e para títulos acadêmicos e científicos, professor, mestre, doutor (BRANDELLI, 2012).

Existe também o elemento chamado de partícula ou conjunção, ao qual se deve ter certa atenção, pois pode ser um elemento fundamental do nome; geralmente o vocábulo vem antes do sobrenome, tendo como exemplos "de", "da", "dos" etc. (BRANDELLI, 2012). Para Amorim (2003, p. 14), "não há qualquer regramento que determine a forma de utilização de partículas ou conjunções, ficando a critério do titular do direito sua escolha e composição, inclusive gramatical". 
Vista a grande importância da individualização da pessoa para a sociedade e sua indispensável identificação perante o Estado, cabe destacar que o nome, de regra, é imutável, se tornando, assim, definitivo, conforme preceitua a Lei dos Registros Públicos. Contudo, em casos excepcionais, será permitida a alteração do nome, em respeito ao princípio da dignidade, casos esses que serão tratados a seguir.

\section{AS POSSIBILIDADES DE ALTERAÇÃO DO NOME CIVIL}

A imutabilidade do nome civil, regra geral, está prevista na Lei dos Registros Públicos (LRP). Nessa linha, se percebe que o nome é o principal modo de identificação de cada indivíduo, e eventual mudança poderia ocasionar confusão diante do Estado e da sociedade. Contudo, pode o indivíduo solicitar a mudança do seu nome, caso apresente motivo plausível para tal, em respeito ao princípio da dignidade humana. Assim, nesta seção, será examinada cada uma das possibilidades de alteração do nome civil, de acordo com a legislação, doutrina e jurisprudência brasileira.

\subsection{Alteração do prenome}

Assim, inicialmente, serão abordados os casos que autorizam a alteração do prenome:

a) apelido público e notório: dispõe o caput do artigo 58 da LRP, com redação dada pela Lei 9.708/98, que o prenome pode ser substituído por apelido público notório. Para Venosa (2012), essa possibilidade de troca vem a ser uma tendência social brasileira, passando a regra da imutabilidade a ser relativa; apesar de já haver julgados favoráveis ao caso, deve o juiz analisar o pedido, se certificando que realmente o indivíduo é conhecido pelo seu apelido;

Caso a alteração do prenome por apelido notório tenha a real intenção de identificar o indivíduo, sendo ele conhecido publicamente pelo seu apelido, nada o impede de solicitar a mudança no seu registro civil. Brandelli (2012) acredita que, além da mudança prevista anteriormente, pode ainda ocorrer o acréscimo do apelido ao nome do indivíduo, visto que traria mudança menos drástica do que a substituição, mesmo que este procedimento não esteja previsto na legislação. Exemplos conhecidos são encontrados, principalmente, em pessoas públicas e artistas, essas sendo mais conhecidas pelo seu apelido do que pelo seu nome, como são os casos da apresentadora Xuxa (Maria da Graça Meneghel), do falecido cantor Cazuza (Agenor de Miranda Araújo Neto) e do ex-presidente Lula (Luiz Inácio da Silva).

b) prenome ridículo: dispõe o parágrafo único do artigo 55 da LRP que os prenomes que causarem constrangimento aos seus portadores não deverão ser registrados pelos oficiais do Registro Civil. Por conseguinte, "o prenome que tenha o condão de expor ao ridículo o 
seu portador não deve sequer ser registrado, facultada a suscitação de dúvida ao juízo competente em caso de inconformidade por parte de quem tenha o direito de dar o nome" (BRANDELLI, 2012, texto digital). Porém, caso haja o registro de prenome ridículo, pode posteriormente ocorrer a sua alteração. Contudo, para Venosa (2012), não apenas o prenome ridículo deve ser evitado, mas também o nome como um todo; mesmo que o prenome não seja ele sozinho vexatório, deve-se cuidar como ficará a pronúncia do prenome juntamente com o nome de família;

É relevante ser observado que pode a percepção de cada um ser diferente quanto ao nome ser ridículo ou não. Se para alguns pode um nome ser considerado vexatório, para outros pode o mesmo nome soar normal. Para melhor demonstrar essa situação, no Brasil, conforme Diniz (2009), há extensa lista de nomes que colocam seu portador ao ridículo, em que se destacam nomes como Céu Azul do Sol Poente, Último Vaqueiro, Sebastião Salgado Doce, Rolando Pela Escada Abaixo, Sum Tin An, Janeiro Fevereiro de Oliveira Março, Remédio Amargo, Amável Pinto, Rego Penteado, Vitor Hugo Tocagaita, Ana Baiana Meleva Daqui Pratinhos, Antônio Veado Prematuro, Restos Mortais de Catarina, dentre muitos outros. Nessa mesma linha acrescenta a autora que há situações em que o nome em si não é vexatório, mas sim imoral, como Hitler ou Lúcifer, e também nomes que dão sentido masculino e feminino, como Juraci, Francis, Eleonor, dentre outros. Situações como nos nomes apresentados autorizam a sua alteração.

c) por quem não tinha o direito de fazê-lo: como são os pais quem têm o direito de dar o nome ao filho, caso haja o registro do nome da criança tendo outra pessoa escolhido o nome, tal ato será considerado inválido, visto que fere o ordenamento jurídico;

No mesmo sentido, explica Brandelli (2012, texto digital):

Uma vez que o ordenamento determina quem tem o direito de dar o nome, se tal direito não for observado quando da inscrição do nome no Registro Civil das Pessoas Naturais, certamente será essa nomeação inválida, podendo, portanto, haver a alteração do nome, no caso aqui, especificamente do prenome, salvo se, diante do caso concreto, uma ponderação racional de princípios conduza para solução diversa.

Vale lembrar o artigo 104 do Código Civil que dispõe que para que um ato tenha validade jurídica requer, dentre outras situações, que seja praticado por agente capaz.

d) pelo uso: apesar de pouco trabalhada essa possibilidade de alteração do nome, é possível a mudança pelo uso; 
Ressalta-se decisão do Tribunal de Justiça do Rio Grande do Sul, com a seguinte ementa:

Ementa: REGISTROS PUBLICOS. IMUTABILIDADE DO PRENOME. INFLUÊNCIA DO USO. RETIFICACAO ADMISSIVEL. A regra da imutabilidade do prenome tem por fim garantir a permanência daquele com que a pessoa se tornou conhecida no meio social: se o prenome lançado no registro jamais identificou seu portador, que por razões outras que mero capricho sempre usou prenome diverso, a retificação é de ser admitida. Solução que se impõe igualmente por constituir o prenome 'Nercio', lançado no registro, mera corruptela do prenome 'Nelson', sempre utilizado pelo apelante, conforme documentalmente comprova. (Apelação Cível N 583050968, Primeira Câmara Cível, Tribunal de Justiça do RS, Relator: Athos Gusmão Carneiro, Julgado em 21/02/1984).

Assim, pode a pessoa também entrar com pedido judicial para a alteração do prenome caso seja conhecida por nome diverso do que consta na certidão de nascimento.

e) primeiro ano após a maioridade: versa o artigo 56 da LRP que o "interessado, no primeiro ano após ter atingido a maioridade civil, poderá, pessoalmente ou por procurador bastante, alterar o nome, desde que não prejudique os apelidos de família, averbando-se a alteração que será publicada pela imprensa". Para essa possibilidade de alteração do nome, o requerente não necessita demonstrar o porquê do pedido, visto que o texto do artigo é claro, autorizando a mudança de nome no primeiro ano após a maioridade, não colocando nenhum obstáculo no pedido, bastando que o interessando junte provas como certidões de processos civis, criminais, eleitorais etc., demonstrando que não está se eximindo de responsabilidades;

Para Brandelli (2012), deve-se atentar com cuidado quanto a essa possibilidade de alteração do nome, pois não se trata de direito potestativo absoluto, visto que não se pode mudar o prenome nem tirar o sobrenome já existente, observando se não vem a prejudicar terceiros nem ocultar ou dificultar a identificação do indivíduo, tendo este cometido algum ilícito ou algo parecido. Por sua vez, observa Coelho (2010) que o interessado na mudança do nome deve ser informado sobre as dificuldades que poderá enfrentar após a alteração, visto que deverá encaminhar novos documentos com o novo nome, assim como registros escolares, assentamentos de saúde, publicações em seu nome, dentre outros.

Salienta-se que, após esse prazo, o pedido de alteração do nome deverá ser feito judicialmente, dando justo motivo para tal, com a participação do Ministério Público e necessitando de sentença procedente do juiz da causa, nos moldes do artigo 57 da Lei 6.015/1973. 
f) nome do estrangeiro: pode a pessoa estrangeira que veio morar no Brasil possuir nome que, na nossa língua, possa ser considerado vexatório, constrangedor, ou até de difícil pronúncia, podendo expor seu portador ao ridículo;

Assim, determina a Lei 6.815/80 que o nome do estrangeiro pode ser alterado, em conformidade com os artigos 43 e 44, competindo ao Ministério da Justiça autorizar a alteração. Assim, pode nessa situação o estrangeiro solicitar a alteração do nome, desde que devidamente comprovado o uso de nome diverso ao seu.

\subsection{Alteração do sobrenome}

São as seguintes as possibilidades de alteração do sobrenome:

a) Casamento: o casamento é uma das hipóteses mais conhecidas de aquisição de sobrenome. Dispõe o parágrafo $1^{\circ}$ do artigo 1.565 do CC que "qualquer dos nubentes, querendo, poderá acrescer ao seu o sobrenome do outro". Ou seja, tanto o marido quanto a esposa podem acrescentar ao seu o sobrenome do cônjuge;

Nessa forma de aquisição/alteração do nome de família, não se exigem muitas formalidades, sendo necessária apenas a declaração de cada um dos cônjuges, se querendo ou não a troca ou acréscimo do sobrenome do outro, quando do registro do casamento. Essas possibilidades independem de autorização do outro, assim como de seus familiares (COELHO, 2010).

b) União estável: dispõe o parágrafo $2^{\circ}$ do artigo 57 da LRP:
Art. 57. [...].
$\S 2^{\circ}$ A mulher solteira, desquitada ou viúva, que viva com homem solteiro, desquitado ou viúvo, excepcionalmente e havendo motivo ponderável, poderá requerer ao juiz competente que, no registro de nascimento, seja averbado o patronímico de seu companheiro, sem prejuízo dos apelidos próprios, de família, desde que haja impedimento legal para o casamento, decorrente do estado civil de qualquer das partes ou de ambas.

Pelo disposto no parágrafo supracitado, será permitida a averbação do patronímico do outro, respeitados os requisitos que constam no próprio artigo. Nos demais parágrafos do artigo, há a exigência, ainda, da expressa concordância do companheiro, tempo mínimo de convivência de cinco anos entre os companheiros ou se existirem filhos dessa união, e se, quando desquitado o companheiro, tenha a ex-esposa sido condenada ou tiver renunciado ao uso dos apelidos do marido, ainda que dele receba pensão alimentícia.

Porém, destaca Brandelli (2012, texto digital), que já não cabe mais a necessidade da ex-esposa ser condenada ou tiver renunciado ao patronímico do marido para a inclusão do nome de família: 
Com efeito, se é possível hoje que um mesmo homem case-se e divorcie-se de cinco mulheres e que todas elas continuem usando o patronímico do ex-marido, por que razão isso não seria possível na união estável, se também ela é entidade familiar reconhecida constitucionalmente? Parece-nos assim revogado tacitamente o $\S 4^{\circ}$, eis que não se coaduna com o regime atual, constitucional e ordinário, da união estável e do casamento.

Como citado no artigo 57 da LRP, há a necessidade de impedimentos para o casamento nessa possibilidade de inclusão do nome. Caso não haja nenhum impedimento para o casamento, por exemplo, se ambos são solteiros, não poderão os companheiros um usar o sobrenome do outro, possibilidade esta apenas com a realização do casamento (GONÇALVES, 2012).

c) Separação e divórcio: o Código Civil atual, apesar de trabalhar bastante sobre a separação e o divórcio, acabou por ser tímido quanto à questão do nome. Para Brandelli (2012), o CC perdeu a oportunidade de trabalhar mais detalhadamente quanto ao nome dos cônjuges, tanto na separação quanto no divórcio, sendo o legislador mais conservador na questão dos direitos da personalidade;

Na separação judicial, destaca-se o artigo 1.578 do CC, dispondo que o cônjuge que for declarado culpado perde o direito de usar o nome de família do outro, caso este tenha anteriormente adotado no casamento, mas desde que tenha requerimento expresso do outro cônjuge, que fora considerado inocente, e que não acarrete prejuízo evidente na identificação da pessoa, a manifesta distinção com relação ao seu nome e o dos filhos havidos dessa relação, ou possível dano grave que seja reconhecido na decisão judicial.

Ainda, com relação ao referido artigo, há os parágrafos $1^{\circ}$ e $2^{\circ}$ afirmando que pode o cônjuge inocente, a qualquer tempo, renunciar ao sobrenome do outro, podendo nos demais casos cada cônjuge escolher pela conservação ou não do nome de casado.

Já quanto ao divórcio, conforme disposto no parágrafo $2^{\circ}$ do artigo 1.571 do CC, pode o cônjuge optar por permanecer com o nome de casado, inclusive em caso de conversão, exceto, neste caso, se disposto em contrário na sentença da separação judicial.

Cabe ressaltar a Emenda Constitucional 66, de 13 de julho de 2010, que deu nova redação ao parágrafo $6^{\circ}$ do artigo 226 da Constituição Federal, em que extinguiu a menção à separação judicial e aos prazos, deixando apenas a dissolução do casamento pelo divórcio. Com isso, de certa maneira derrogaramse alguns artigos do Código Civil, mas não os excluiu em definitivo, visto que nada fala sobre proibição, mas apenas de derrogação. Então, as partes que tratam sobre o nome continuam valendo (BRANDELLI, 2012).

d) Nulidade ou anulação do casamento: nesses casos, importante analisar o caso em que se pede a anulação ou a nulidade do 
casamento, inclusive com relação à volta do nome de casado para solteiro, visto que pode vir a prejudicar a pessoa quanto à questão de sua identificação e com relação aos filhos do casal.

e) Homonímia: inicialmente, explica-se que a homonímia é a situação em que há identidade de pronúncia ou de grafia (RIOS, 1999), ou seja, em que há pessoas que recebem o mesmo nome. Nessas situações, pode a pessoa, demonstrando problemas e prejuízos acerca dessa situação, entrar com pedido judicial para alteração do nome, retificando, assim, seu registro de nascimento.

f) Reconhecimento e negatória de paternidade: nos casos de reconhecimento de paternidade, tem o filho o direito de pôr o sobrenome do pai em seu registro de nascimento. Da mesma forma, nos casos em que o filho recebeu o sobrenome do suposto pai, e posteriormente fora descoberto que o pai registrado não é o genitor biológico, pode o filho perder o direito de carregar o sobrenome deste;

A respeito da negatória de paternidade, cabe ressaltar que se for entendida a paternidade socioafetiva entre o pai registral e o filho, não terá êxito o pedido negatório. Para melhor ilustrar essa situação, já decidiu o Tribunal de Justiça do Rio Grande do Sul:

Ementa: APELAÇÃO CÍVEL. NEGATÓRIA DE PATERNIDADE. PATERNIDADE SOCIOAFETIVA. Ainda que o autor, pai registral, não seja o pai biológico do réu, mantém-se a improcedência da negatória da paternidade, se estabelecida a paternidade socioafetiva entre eles. Em se tratando de relação de filiação, não se pode compreender que seja descartável, ao menos em casos como o presente, onde por vinte anos o réu teve como genitor o autor. Pretensão que afronta o princípio constitucional da dignidade da pessoa humana, porque o réu ficaria sem pai registral, ou seja, sem filiação e sobrenome paterno. Precedentes doutrinários e jurisprudenciais. Apelação desprovida. (Apelação Cível $\mathrm{N}^{\circ}$ 70022895072, Oitava Câmara Cível, Tribunal de Justiça do RS, Relator: José Ataídes Siqueira Trindade, Julgado em 05/06/2008).

Conforme a decisão, tal pretensão afrontaria o princípio constitucional da dignidade da pessoa humana, visto que o filho ficaria sem sobrenome paterno.

g) Abandono paterno ou materno e do vínculo socioafetivo: nos casos de abandono do filho, seja paterno, seja materno, a jurisprudência tem entendido por reconhecer a possibilidade de alteração do nome de família, visto que o sobrenome identifica a origem familiar, e em sendo indivíduo abandonado pelo pai ou pela mãe, em 
nada faz sentido permanecer com o sobrenome deste ou daquele (BRANDELLI, 2012);

O Tribunal de Justiça do Rio Grande do Sul julgou procedente um pedido de exclusão do patronímico fundamentado em abandono paterno:

Ementa: APELAÇÃO CÍVEL. REGISTRO CIVIL. EXCLUSÃO DO PATRONÍMICO PATERNO FUNDAMENTADO NO ABANDONO PSICOLÓ-GICO E MATERIAL. POSSIBILIDADE. PRECEDENTES DA CORTE. NECESSIDADE, TODAVIA, DE DILAÇÃO PROBATÓRIA A FIM DE COMPROVAR AS ALEGAÇÕES DA PARTE REQUERENTE. SENTENÇA DESCONSTITUÍDA. APELO PROVIDO. (Apelação Cível N 70040638918, Sétima Câmara Cível, Tribunal de Justiça do RS, Relator: Roberto Carvalho Fraga, Julgado em 23/11/2011).

Também, a jurisprudência tem aceitado a inclusão de sobrenome do padrasto ou madrasta com quem tenha reconhecido vínculo socioafetivo. Nessa linha, é relevante se observar a decisão do Supremo Tribunal Federal (STF) em 21/09/2016, em tema de Repercussão Geral 622, relatado pelo ministro Luiz Fux, quando foi deliberada que não há prevalência entre as modalidades de vínculo parental (paternidade biológica e paternidade socioafetiva), deliberando que ambas as possibilidades poderiam coexistir (CALDERON, 2016).

A LRP, em seu artigo 57, § $8^{\circ}$, incluído pela Lei 11.924/2009, dispõe que o enteado ou a enteada poderão requerer a averbação do sobrenome do padrasto ou madrasta no registro de nascimento, havendo justo motivo e respeitando outros parágrafos do mesmo artigo, além de que haja concordância de quem está cedendo seu nome de família, sem prejuízo do mesmo.

h) Mudança de nome dos ascendentes: nessa situação, caso haja a mudança do nome de família da pessoa, pode seus descendentes, caso for possível, solicitar também a alteração. Mais comum ocorrer é no caso de erro gráfico, em que se alterando, por exemplo, uma letra do sobrenome, têm seus descendentes e sua esposa o direito de também corrigir o erro (BRANDELLI, 2012).

Mesmo com a regra da imutabilidade do nome, há outros casos da vida que pedem alterações, como descritos na sequência.

\subsection{Outras situações que autorizam a alteração do nome}

Para finalizar, serão demonstradas outras situações de alteração do nome, que autorizam, por exemplo, a mudança do nome num todo:

a) Para proteção de vítimas e testemunhas de crimes: essa possibilidade de alteração do nome tem o intuito de proteger a identidade do indivíduo que foi vítima ou testemunha de crime, esteja ele sendo ameaçado ou por estar ajudando em investigações criminais. 
Eventualmente pode também ser aplicada ao cônjuge, filhos e demais familiares da vítima ou testemunha;

Seguindo o disposto da Lei 9.807/1999, o processo proceder-se-á pelo rito sumaríssimo e correrá em segredo de justiça. Após, sendo outorgado o pedido, será realizada a alteração nos registros de nascimento. Se cessada a ameaça, fica facultado ao protegido o pedido para o retorno a seu nome original, que deverá ser feito judicialmente em petição que será encaminhada pelo Conselho Deliberativo, tendo manifestação prévia do Ministério Público.

b) Adoção: que atualmente é regida pela Lei 12.010/2009, o adotado não conserva o sobrenome de seu pai de sangue, conforme determinado no caput do artigo 41 do Estatuto da Criança e do Adolescente (ECA), em virtude do desligamento de qualquer vínculo com os pais ou parentes, acrescentando o patronímico do adotante, conforme disposto no parágrafo $5^{\circ}$, do artigo 47 do ECA.

Assim, conforme Brandelli (2012), sendo rompido o vínculo com a família biológica, passa o adotado a obter os mesmos direitos dos outros filhos na sua nova família, inclusive quanto ao sobrenome, em que se retira o da sua família biológica e, em substituição, inclui-se da família adotiva, visto que não terá mais qualquer vínculo com aquela.

Pode também a família adotiva, conforme disposto no ECA, no artigo 47 , em seu parágrafo $5^{\circ}$, parte final, determinar a alteração do prenome do adotado, inclusive se maior de idade. Contudo, o pedido de alteração de prenome precisa necessariamente ser feito quando da adoção, com processo em curso, não sendo permitida a troca após esse período. Depois do deferimento da adoção em sentença judicial, expede-se mandado para cancelamento do registro original do adotado, para então ser lavrado outro, acrescentando-se o nome dos pais adotivos, assim como os dos novos avós do adotado, sendo possível a troca do nome. Assim, percebe-se que essa possibilidade de alteração permite tanto a mudança do prenome quanto a do sobrenome.

c) Descoberta do verdadeiro nome: trata-se de rara, mas possível situação. São casos, por exemplo, em que há uma criança abandonada, seja na rua, seja em abrigos, em que não se sabe o seu nome. Ao descobrir o verdadeiro nome, pode a pessoa ou interessado solicitar a alteração do nome, pois descoberto o verdadeiro nome não faz sentido manter o que lhe foi dado, visto esse ser apenas transitório (BRANDELLI, 2012).

d) Não correspondência do assento com a declaração: nessa situação, cabe à pessoa, seja o pai, seja a mãe, ou os dois, que informou o nome ao Oficial Registrador provar que este errou ao redigir o nome no registro de nascimento. Assim, caso seja provado que o nome dado pelos responsáveis está diferente do registrado, permite-se 
a alteração do nome, visto que compromete a validade do ato, este estando viciado (BRANDELLI, 2012).

e) Erro gráfico: os erros de grafia, normalmente, acontecem na transcrição do nome da pessoa na certidão de nascimento, feita pelo Oficial de Registro Civil das Pessoas Naturais. Muitas vezes, em nada altera a pronúncia do nome, e sim uma ou duas letras, comprovando documentalmente como deveria ser o nome registrado, como, por exemplo, Beatriz, com a letra " $\mathrm{z}$ " no final, em vez de Beatris, com " $\mathrm{s}$ ".

Conforme o caput do artigo 110 da LRP, nos casos de "erros que não exijam qualquer indagação para a constatação imediata de necessidade de sua correção", pode o requerente comparecer ao próprio Registro Civil onde fora registrado e solicitar com o Oficial de Registro a correção, apresentando em petição assinada, após manifestação positiva do Ministério Público. Ainda, nos casos de dúvidas e solicitação de provas, observam-se os parágrafos do referido artigo.

f) Mudança de sexo: nos casos de transexualismo, têm os tribunais, atualmente, julgado procedentes os pedidos de retificação do nome. Para Coelho (2010), as pessoas que se habilitam a cirurgia para mudança de sexo têm o direito de possuir prenome compatível com sua nova aparência. Conforme o autor, têm-se conhecido com mais facilidade nos processos judiciais quando se consegue demonstrar que a pessoa tem perturbação fisiológica e distúrbios psíquicos, sendo recomendado mudar de sexo por meio de cirurgia. Contudo, há decisões judiciais de alteração do nome sem cirurgia de troca de sexo.

Cabe salientar também que os transexuais e travestis têm a opção de usar seu nome social, no âmbito da administração pública federal direta, autárquica e fundacional, nos termos do Decreto 8.727/2016.

\section{CONCLUSÃO}

Sendo o nome civil elemento essencial para identificação de cada indivíduo, a opção pela mudança, com motivação e devidamente fundamentada, vem sendo aceita no nosso sistema jurídico. A ideia de ter um nome diferente do que fora registrado na certidão de nascimento tem se tornado aceitável, visto que, apesar da regra da imutabilidade, a intenção é o bem-estar da pessoa, respeitando a situação atual de cada indivíduo, analisando cada situação para que se tenha certeza de que não se trate de fraudes ou que prejudique terceiros.

Diante da análise do problema proposto para este estudo - tendo em vista a regra geral da imutabilidade do nome da pessoa natural, em quais casos é permitida a mudança dessa identificação social? - pode-se concluir que a hipótese inicial para o questionamento se confirma, pois tendo motivo plausível para solicitar a mudança e sendo possível observando as possibilidades de 
mudança referidas na última seção do artigo, pode a pessoa solicitar judicial ou extrajudicialmente, conforme o caso, a alteração do nome.

Além disso, apesar de as possibilidades de alteração do nome civil serem taxativas pelas normas brasileiras, doutrinadores têm trabalhado sobre outros casos de mudança, e a jurisprudência tem decidido em várias possibilidades de retificação do nome, visto que as motivações são diversas, muitas delas com reais condições de mudança, como nas situações de erros gráficos, adoção, transexualismo.

Portanto, entende-se ser possível a mudança do nome civil da pessoa natural, observando cada situação em particular, na percepção de que a mudança trará reais benefícios ao seu portador e não acarretará prejuízos a terceiros, e, principalmente, em respeito à dignidade humana das pessoas envolvidas.

\section{REFERÊNCIAS}

AMORIM, José Roberto Neves. Direito ao nome da pessoa física. São Paulo: Saraiva, 2003.

BRANDELLI, Leonardo. Nome civil da pessoa natural. São Paulo: Saraiva, 2012. E-book. Disponível em: <http:/ /www.univates.br/biblioteca>. Acesso em: 10 out. 2016.

\section{BRASIL. Constituição (1988). Constituição da República Federativa do}

Brasil. Disponível em: <http://www.planalto.gov.br/ccivil_03/constituicao/ constituicaocompilado. htm>. Acesso em: 05 set. 2016.

BRASIL. Constituição (1988). Emenda Constitucional no 66, de 13 de julho de 2010. Dá nova redação ao $\S 6^{\circ}$ do art. 226 da Constituição Federal, que dispõe sobre a dissolubilidade do casamento civil pelo divórcio... Disponível em: <http:/ /www. planalto.gov.br/ccivil_03/constituicao/emendas/emc/emc66.htm>. Acesso em: 04 nov. 2016.

BRASIL. Decreto-Lei ${ }^{\circ} 8.727$, de 28 de abril de 2016. Uso do nome social. Disponível em: <https://www.planalto.gov.br/ccivil_03/_Ato2015-2018/2016/Decreto/D8727. htm>. Acesso em: 07 nov. 2016.

BRASIL. Lei no . 6.015, de 31 de dezembro de 1973. Lei dos Registros Públicos. Disponível em: <http://www.planalto.gov.br/ccivil_03/leis/L6015compilada.htm>. Acesso em: 10 out. 2016.

BRASIL. Lei no . 6.815, de 19 de agosto de 1980. Estatuto do Estrangeiro. Disponível em: <http://www.planalto.gov.br/ccivil_03/leis/L6815.htm>. Acesso em: 03 nov. 2016. 
BRASIL. Lei n ${ }^{\circ} .8 .069$, de 13 de julho de 1990. Estatuto da Criança e do Adolescente. Disponível em: <http://www.planalto.gov.br/ccivil_03/leis/L8069Compilado.htm>. Acesso em: 03 nov. 2016.

BRASIL. Lei $n^{\circ} .9 .807$, de 13 de julho de 1999. Lei de proteção a vítimas e testemunhas. Disponível em: < http://www.planalto.gov.br/ccivil_03/leis/L9807. htm>. Acesso em: 03 nov. 2016.

BRASIL. Lei no $n^{\circ}$ 10.406, de 10 de janeiro de 2002. Código Civil. Disponível em: <http://www.planalto.gov.br/ccivil_03/leis/2002/L10406compilada.htm>. Acesso em: 05 set. 2016.

BRASIL. Lei no. 12.010, de 03 de agosto de 2009. Nova Lei da Adoção. Disponível em: <http://www.planalto.gov.br/ccivil_03/_ato2007-2010/2009/lei/112010.htm>. Acesso em: 03 nov. 2016.

CALDERÓN, Ricardo. Processo familiar: Reflexos da decisão do STF de acolher socioafetividade e multiparentalidade. Conjur, São Paulo, 25 set. 2016. Disponível em: <http:/ / www.conjur.com.br/2016-set-25/processo-familiar-reflexos-decisao-stfacolher-socioafetividade-multiparentalidade>. Acesso em: 15 nov. 2016.

COELHO, Fábio Ulhoa. Curso de Direito Civil: parte geral. 4. ed. São Paulo: Saraiva, 2010. v. 1.

DINIZ, Maria Helena. Curso de Direito Civil brasileiro: teoria geral do Direito Civil. 26. ed. São Paulo: Saraiva, 2009. v. 1.

FIUZA, César. Direito Civil: curso completo. 17. ed. Belo Horizonte: Del Rey, 2014.

GONÇALVES, Carlos Roberto. Direito Civil brasileiro: parte geral. 12. ed. São Paulo: Saraiva, 2014. v. 1.

MEZZAROBA, Orides; MONTEIRO, Cláudia S. Manual de metodologia da pesquisa no Direito. 6. ed. São Paulo: Saraiva, 2014.

RIO GRANDE DO SUL. Tribunal de Justiça. Apelação Cível Nº 583050968, da Primeira Câmara Cível. Apelante: Nercio R. S. Apelado: Ministério Público. Relator: Athos Gusmão Carneiro. Porto Alegre, 21 fev. 1984. Disponível em: <http:/ /www.tjrs. jus.br/busca/>. Acesso em: 22 out. 2016.

RIO GRANDE DO SUL. Tribunal de Justiça. Apelação Cível No 70022895072, da Oitava Câmara Cível. Apelante: A.L.. Apelado: T.L.. Relator: José Ataides Siqueira Trindade. Porto Alegre, 05 jun. 2008. Disponível em: < http://www.tjrs.jus.br/ busca/>. Acesso em: 22 out. 2016.

RIO GRANDE DO SUL. Tribunal de Justiça. Apelação Cível No 70040638918, da Sétima Câmara Cível. Apelante: A. L. L. P. Apelado: Justiça Pública. Relator: Roberto Carvalho Fraga. Porto Alegre, 23 nov. 2011. Disponível em: <http:/ / www.tjrs.jus.br/ busca/>. Acesso em: 03 nov. 2016. 
RIOS, Dermival Ribeiro. Minidicionário escolar da língua portuguesa. São Paulo: DCL, 1999.

RIZZARDO, Arnaldo. Parte geral do Código Civil: Lei n ${ }^{\circ} 10406$, de 10.01.2002. 3. ed. Rio de Janeiro: Forense, 2005.

VENOSA, Sílvio de Salvo. Direito Civil: parte geral. 12. ed. São Paulo: Atlas, 2012. v. 1. 